\title{
Article \\ Purple Corn Silk Extract Attenuates UVB-Induced Inflammation in Human Keratinocyte Cells
}

\author{
Watcharaporn Poorahong ${ }^{1}\left(\mathbb{D}\right.$, Sukanda Innajak ${ }^{1}$, Malyn Ungsurungsie ${ }^{2}$ and Ramida Watanapokasin ${ }^{1, *(D)}$ \\ 1 Department of Biochemistry, Faculty of Medicine, Srinakharinwirot University, Bangkok 10110, Thailand; \\ noi.poorahong@gmail.com (W.P.); suinnajak@gmail.com (S.I.) \\ 2 Faculty of Pharmacy, Mahidol University, Bangkok 10400, Thailand; malyn@snjinter.com \\ * Correspondence: ramidabc@gmail.com or ramidaw@g.swu.ac.th; Tel.: +66-8247-97824
}

Citation: Poorahong, W.; Innajak, S.; Ungsurungsie, M.; Watanapokasin, R. Purple Corn Silk Extract Attenuates UVB-Induced Inflammation in Human Keratinocyte Cells. Sci. Pharm. 2022, 90, 18. https://doi.org/ 10.3390/scipharm90010018

Academic Editor: Natasa Skalko-Basnet

Received: 22 January 2022 Accepted: 25 February 2022 Published: 1 March 2022

Publisher's Note: MDPI stays neutral with regard to jurisdictional claims in published maps and institutional affiliations.

Copyright: (c) 2022 by the authors. Licensee MDPI, Basel, Switzerland. This article is an open access article distributed under the terms and conditions of the Creative Commons Attribution (CC BY) license (https:// creativecommons.org/licenses/by/ $4.0 /)$.

\begin{abstract}
UVB is a causative factor for severe skin damage, such as cell aging, death, and inflammation. UVB easily permeates into the epidermis layer of human skin, which is mainly composed of keratinocyte cells. In previous results, we found that purple corn silk (PCS) extract showed the potential to inhibit keratinocyte damages of UVB-treated cells. Thus, in this study, we aimed to evaluate the preventive effects of PCS extract against the inflammation of UVB-induced keratinocyte cells using the HaCaT cell line. HaCaT cells were treated with PCS extract at various concentrations for $1 \mathrm{~h}$, then exposed to $25 \mathrm{~mJ} / \mathrm{cm}^{2} \mathrm{UVB}$ before subsequent experiments. Fragmented DNA was observed using flow cytometry. The inflammatory response was investigated through NF- $\mathrm{B}$ activity by immunofluorescence staining and related protein expression by Western blotting. The results demonstrated that PCS extract decreased the sub-G1 DNA content. Interestingly, PCS extract attenuated NF- $\mathrm{kB}$ activity via suppressed NF- $\mathrm{kB}$ nuclear translocation and protein expression. Moreover, PCS extract remarkably decreased c-Jun phosphorylation and decreased proinflammatory cytokines, along with iNOS and COX-2 levels in UVB-treated cells compared to the UVB-control group. This finding exhibited that PCS extract minimized inflammation in keratinocyte cells induced by UVB radiation.
\end{abstract}

Keywords: keratinocyte; skin cells; UVB-protection; purple corn silk; inflammation

\section{Introduction}

Solar ultraviolet (UV) light is composed of UVA (320-400 nm), UVB (280-320 nm), and UVC (200-280 nm). UVC is completely blocked by the ozone layer, while only $90-95 \%$ of UVA and $5-10 \%$ of UVB reach the Earth and affect human skin. While the level of UVB reaching the ground is lower, UVB energy is more harmful than UVA. Most of the UVB radiation can permeate into the epidermis layer, which is composed of at least $80 \%$ keratinocyte cells. Numerous studies reported that UVB exposure to the skin can stimulate intracellular reactive oxygen species (ROS) overproduction, mediated oxidative damage, and enhanced risk of skin carcinogenesis [1-4].

ROS play an important role in the initiation and induction of an inflammatory response. ROS induce oxidative damage by oxidizing and modifying various cellular molecules such as lipids, DNA, and proteins [1,4-6]. During skin exposure to UVB, the intracellular ROS is increased and mediates activation of transcription factors, including nuclear factorkappa B (NF- $\kappa B$ ). In latent stages, NF- $\mathrm{BB}$ associated with an inhibitor of $\kappa \mathrm{B}$ (I $\kappa \mathrm{Bs})$ is in an inactive form. The excessive intracellular ROS molecules can drive modification of IkBs proteins, which leads to their degradation through ubiquitination. This event activates NF- $k B$ translocation from the cytosol into the nucleus, followed by up-regulating the gene expression of inflammatory mediators such as interleukins (ILs), cyclooxygenase-2 (COX2 ), and inducible nitric oxide synthase (iNOS) [5,7-10]. Likewise, UVB and intracellular ROS mediate the induction of mitogen-activated protein kinases (MAPKs), especially p38 
MAPKs and c-Jun NH2-terminal kinase (JNK). JNK mostly activates c-Jun phosphorylation at a positive regulatory domain, thereby activating the transcription of various genes. Previous studies suggested that $\mathrm{p} 38$ MAPKs and JNK are primarily responsible for oxidative stress as well as UV radiation. p38 MAPKs and c-Jun promote the AP-1 complex, which can turn on gene expression to enhance skin inflammation [11-16].

Therefore, in this study, we demonstrated that UVB and intracellular ROS are associated with skin inflammation. In a previous publication, we found that the purple corn silk (PCS) extract showed antioxidant power through scavenging free radicals and decreased intracellular ROS in UVB-treated HaCaT cells [17]. Corn silk, part of a kind of female corn, is an important source of polyphenols. Some reports indicated that purple corn silk extract is rich in anthocyanin as a major component [18-24]. However, information about the role of PCS extract against UVB-induced inflammation in keratinocyte cells is not yet investigated. Hence, in this study, we described the potential of PCS extract against the UVB-induced inflammatory response in keratinocyte $\mathrm{HaCaT}$ cells.

\section{Results}

\subsection{UV-Absorbing Properties of PCS Extract}

Generally, the epidermal layer acts as the first line of defense against solar UV through UV absorb. The PCS extract can minimize the effects of UV on skin cells, as shown in Figure $1 ; 1 \mathrm{mg} / \mathrm{mL}$ of PCS extract can absorb mainly the UVB. These data indicate that PCS extract acted as physical UVB protection, preventing UVB energy from entering skin keratinocyte cells.

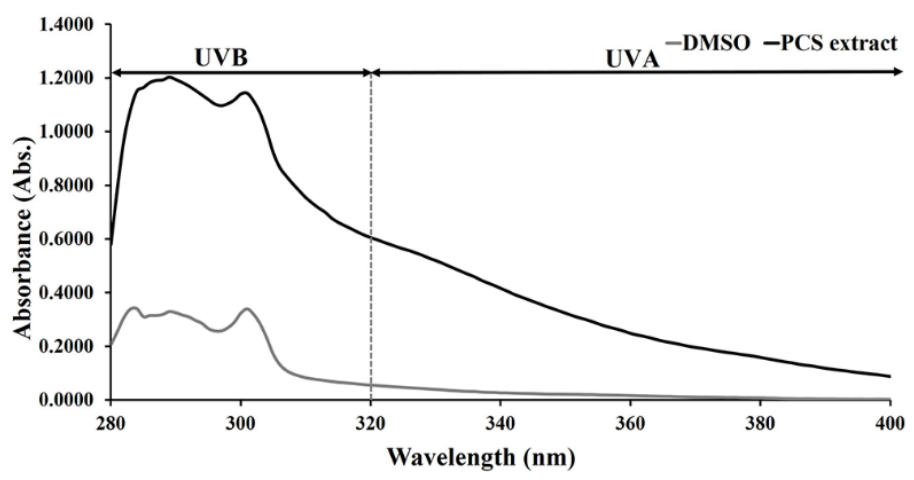

Figure 1. A spectrum of UV absorbance of PCS extract. The gray line shows UV absorbance of DMSO used as a negative control. The black line shows UV absorbance of PCS extract at $1 \mathrm{mg} / \mathrm{mL}$ (in DMSO). The UV absorbance was measured every $1 \mathrm{~nm}$ covering a range of 280-400 $\mathrm{nm}$ UVA and UVB wavelengths using a spectrophotometer.

\subsection{PCS Extract Attenuated UVB-Induced Cell Death in HaCaT Cells}

In a previous study, we demonstrated that PCS extract at concentrations of $0.3,0.5$, and $1 \mathrm{mg} / \mathrm{mL}$ prevented cell death in UVB-treated cells [17]. Therefore, in this study, flow cytometry was conducted to examine the sub-G1 population, indicating fragmented DNA in dead cells. These results were used to confirm the anti-cell-death activity of PCS extract before subsequent experiments. The result showed that the UVB-control group significantly increased sub-G1 content at level $p<0.001$ compared to the non-UVB group, whereas PCS extract reduced cell death higher than the UVB-control group (Figure 2). This result confirms that PCS extract inhibits cell death induction in UVB-treated HaCaT cells. 
(a)
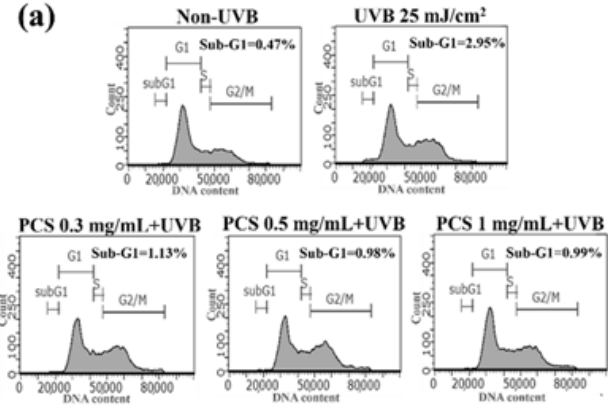

(b)

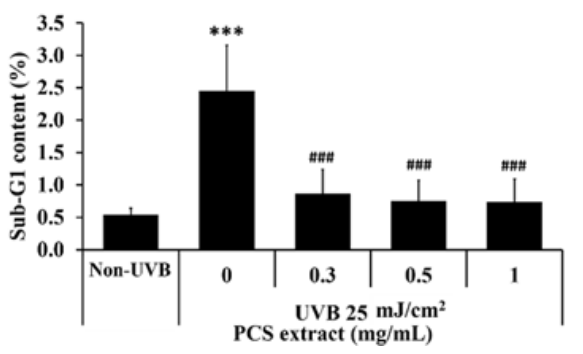

Figure 2. Effect of PCS extract on UVB-induced cell death in HaCaT cells. Cells were pre-treated with PCS extract for $1 \mathrm{~h}$ and exposed to $25 \mathrm{~mJ} / \mathrm{cm}^{2} \mathrm{UVB}$ followed by incubation in fresh medium for $24 \mathrm{~h}$. Then, DNA contents of the cells were determined using flow cytometry analysis. Cellular DNA was fixed and stained with Guava cell cycle ${ }^{\circledR}$ reagent. (a) Histogram of cell cycle distribution. (b) Sub-G1 content. Results are the average values $\pm \operatorname{SD}(n=3) .{ }^{* * *} p<0.001$; vs. the non-UVB group and \#\#\# $p<0.001$ vs. the UVB control group.

\subsection{PCS Extract Decreases NF- $\kappa B$ Activity in UVB-Treated HaCaT Cells}

The increased NF- $\kappa B$ function relates to cellular inflammation. Immunofluorescence staining was used to determine NF- $k$ B activity via monitoring the translocation of NF- $k B$ from the cytosol into the nucleus. The results demonstrated that UVB increased NF$\mathrm{KB}$ nuclear translocation compared to the non-UVB group. In contrast, cells pre-treated with PCS extract showed a strong attenuation of this event compared to the UVB-control group in a dose-dependent manner, as shown in Figure 3a. Furthermore, we found that UVB significantly increased NF- $\mathrm{B}$ protein expression, which was inhibited by PCS extract (Figure $3 b$ ). These results indicated that PCS extract suppressed NF- $k$ B nuclear translocation and protein expression in UVB-induced HaCaT cells.

(a)

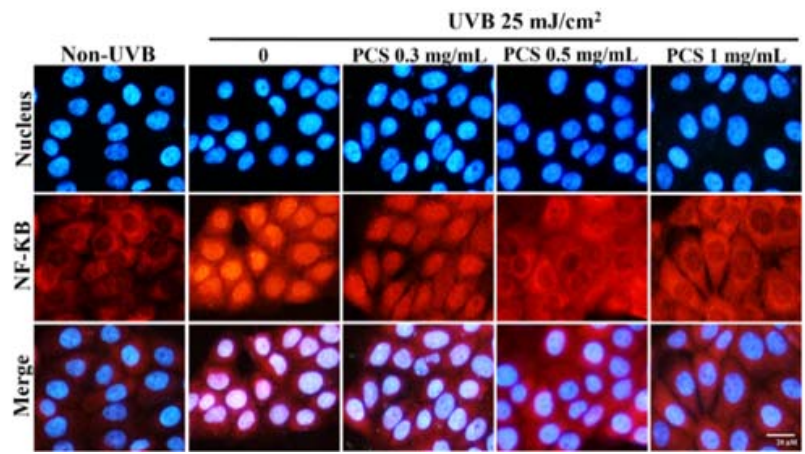

(b)

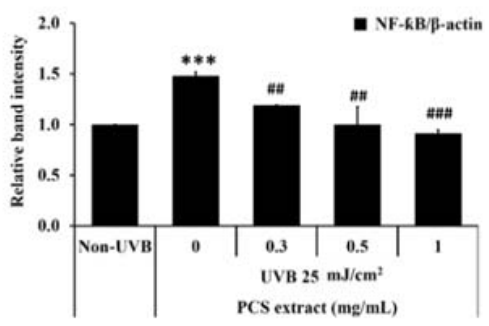

Figure 3. Protective effect of PCS extract on UVB-induced NF- $k B$ activity in HaCaT cells. After pre-treating cells with PCS extract for $1 \mathrm{~h}$, cells were exposed to UVB, followed by incubation in fresh medium for $1 \mathrm{~h}$. Then, cells were analyzed by immunofluorescence staining and Western blotting. (a) Images represent translocation of NF- $\mathrm{kB}$, AlexaFloure-546 (red color) indicates NF- $\mathrm{kB}$ localization, and counterstain using Hoechst33342 (blue color) indicated nuclei. (b) The histogram presents the relative band intensity of NF- $\mathrm{kB}$ protein expression after normalization with the internal control ( $\beta$-actin). Results were the average values \pm SD $(n=3) .{ }^{* * *} p<0.001$ vs. non-UVB group and \#\# $p<0.01 ; \# \#$ p $<0.001$ vs. the UVB control group.

\subsection{PCS Extract Reduced Proinflammatory Cytokine Expression in UVB-Treated HaCaT Cells}

In a subsequent experiment, we investigated the expression of proinflammatory cytokines regulated by NF- $\mathrm{KB}$ activities, including iNOS and COX-2. In unstimulated keratinocyte cells, these proteins were at a low level. In contrast, upon the stimulation of HaCaT cells by UVB irradiation, both iNOS and COX-2 levels were significantly increased 
$(p<0.001)$ compared to the non-UVB group, whereas $0.3,0.5$, and $1 \mathrm{mg} / \mathrm{mL}$ of PCS extract significantly decreased iNOS and COX-2 levels when compared to the UVB-control group, as shown in Figure 4. These findings prove that PCS extract was an effective inhibitor in the inflammation process in UVB-exposed human keratinocyte cells.

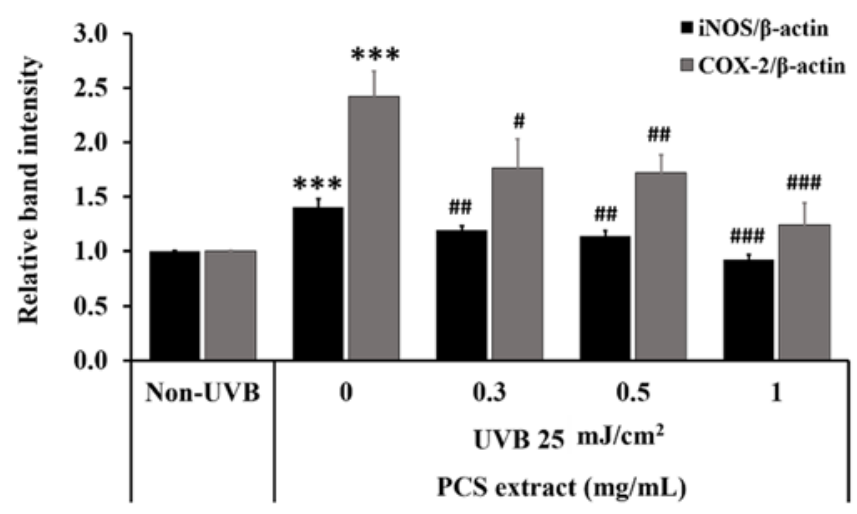

Figure 4. Inhibitory effect of PCS extract on UVB-induced proinflammatory cytokines in HaCaT cells. Cells were pre-treated with PCS extract for $1 \mathrm{~h}$ before UVB irradiation. After $24 \mathrm{~h}$, cells lysates were analyzed by Western blot analysis. The histogram presents the relative band intensity of iNOS and COX-2 protein expression after normalization with the internal control ( $\beta$-actin). Results are the mean average $\pm \mathrm{SD}(n=3) .{ }^{* * *} p<0.001$ vs. the non-UVB group and $\# p<0.05 ; \# \#<0.01$; \#\#\# $p<0.001$ vs. the UVB control group.

\subsection{PCS Extract Decreased UVB-Induced MAPKs Phosphorylation in UVB-Treated HaCaT Cells}

Further, we monitored the influence of UVB on the phosphorylation of stress-sensitive MAPKs family proteins by Western blot analysis. The results demonstrated that UVB increased p38 and c-Jun phosphorylation at the levels of $p<0.05$ and $p<0.001$, respectively, compared to the non-UVB group (Figure 5). In contrast, PCS extract slightly reduced phosphorylated p38 with no statistically significant difference $(p<0.001)$ compared to the UVB-control group. Remarkably, PCS extract strongly inhibited the phosphorylated c-Jun protein level in a dose-dependent manner compared to the UVB control group at a value of $p<0.001$, as shown in Figure 5. These results show that PCS extract primarily suppressed c-Jun phosphorylation in the UVB-irradiated HaCaT cells.

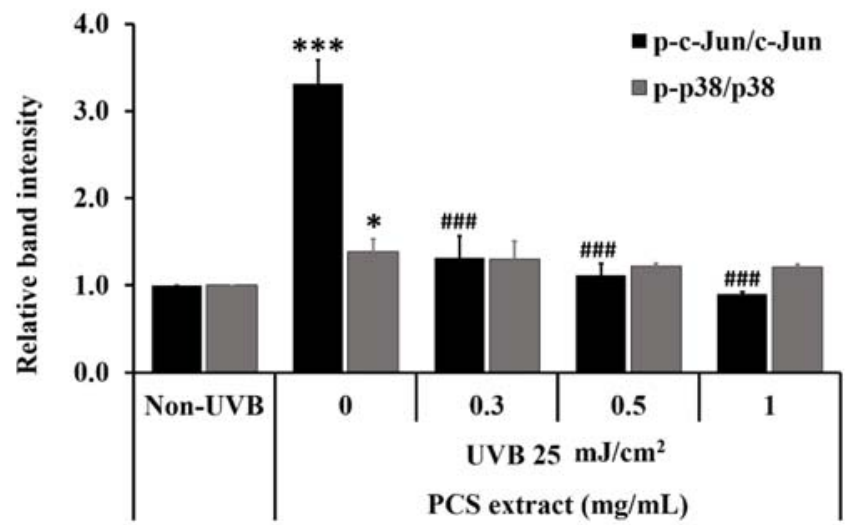

Figure 5. Protective effect of PCS extract on UVB-induced MAPKs phosphorylation in HaCaT cells. After pretreatment of the cells with PCS extract for $1 \mathrm{~h}$, cells were exposed to UVB followed by incubation in fresh medium for $24 \mathrm{~h}$. Then, cells were analyzed by Western blotting. The histogram presents the relative band intensity of a ratio between phosphorylated-form and total-form. Results were the average values $\pm \operatorname{SD}(n=3) .{ }^{*} p<0.05 ;{ }^{* * *} p<0.001$ vs. the non-UVB group and \#\#\#; $p<0.001$ vs. the UVB control group. 


\section{Discussion}

The outermost layer of human skin, known as the epidermis layer, is prominently composed of keratinocyte cells, which serve as a physical barrier against environmental insults such as pathogens, chemicals, and harmful radiation, especially solar UVB radiation. UVB radiation reaching the Earth accounts for only around $4-5 \%$ of total solar UV. However, solar UVB is an important inducer of photoaging, sunburn, wrinkles, inflammation, skin cell death, and increased risk of skin carcinogenesis in keratinocyte cells [1-4,13,25-27].

Natural plants are abundant sources of phytonutrients potent as antioxidant agents such as polyphenols, flavonoids, anthocyanins, carotenoids, and lutein. In the case of purple corn, the evidence reported that purple corn and purple maize pigment extract are rich in anthocyanin $[18,19,28,29]$. Similarly, a section of a kind of female corn (corn silk) is an important source of polyphenols. The ethanol and aqueous extract of purple corn silk possesses abundant polyphenol components, especially anthocyanins. In addition, these extracts showed antioxidant power through scavenging free radicals and enhancing antioxidant enzyme activities [20-24]. In our previous report, screening based on visible color changes of anthocyanin towards different $\mathrm{pH}$ values showed that adding $2 \mathrm{~N}$ hydrochloric acid $(\mathrm{HCl})$ to PCS extract appeared as a pink-red color that turned deep green upon ammonia addition, which predicted that PCS extract might be rich in anthocyanin content. Moreover, the free-radical scavenging activity of PCS extract was investigated by using a 2,2-Diphenyl-1-(2,4,6-trinitrophenyl) hydrazyl (DPPH) assay. The effective concentration (EC50) value of PCS extract was at $0.53 \mathrm{mg} / \mathrm{mL}$ [17]. However, the phytochemicals of PCS extract need to be further confirmed.

Recently, the beneficial properties of phytonutrients in UV prevention were discovered. Previous studies found that purple corn silk extract showed potential activity against cell damage in human keratinocyte cells stimulated by UVB irradiation [17]. In this study, we were interested in the specific effects of PCS extract on human keratinocyte cells through evaluating its activity against UVB-induced skin inflammation. We found that $25 \mathrm{~mJ} / \mathrm{cm}^{2}$ of UVB increased fragmented DNA in the UVB-treated HaCaT cells, which was attenuated by PCS extract. Hence, our results confirmed that the PCS extract prevented DNA fragmentation and cell death in the UVB-treated HaCaT cells. Generally, UVB energy induces intracellular ROS generation. Accumulated cellular ROS significantly stimulates skin inflammation. According to previous studies, PCS extract attenuates free radicals and the overproduction of ROS in HaCaT cells induced by UVB [17], and we hypothesized that PCS extract might prevent UVB-induced inflammatory response in keratinocyte cells, as it is well known that ROS directly related to NF- $\mathrm{kB}$ activation is a key mediator of inflammation regulating gene expression, including COX-2, iNOS, TNF- $\alpha$, IL-6, IL-8, and IL$1 \beta[8,30,31]$. In keratinocyte cells, NF- $\mathrm{kB}$ increased the sensitivity of inflammatory response in UVB-irradiated cells and promoted inflammatory cytokine expression [7,16,32-34]. Interestingly, many reports showed that phytonutrients, especially a group of phenolic and proanthocyanidins, effectively attenuated NF- $\mathrm{KB}$ activities [19]. In this study, we found that PCS extract significantly inhibited the NF- $\mathrm{KB}$ activation stimulated by UVB. In addition, we observed that PCS extract decreased iNOS and COX-2 levels in the UVB-treated $\mathrm{HaCaT}$ cells. Likewise, previous studies suggested that UVA- and UVB-induced skin inflammation through NF- $\mathrm{kB}$ activation led to increased various inflammatory cytokines, which were attenuated by anthocyanin-rich extracts such as raspberry, black soybean, and strawberry extract $[26,35,36]$. However, we suggested that the downstream of COX-2 and iNOS involved in the inflammatory process needs to be explored to fully understand the anti-inflammatory effects of PCS extract against UVB in human keratinocyte cells.

The activation of MAPK proteins is known as a direct intracellular response signaling pathway that stimulates the expression of various target genes. Most evidence suggests that UVB strongly activates stress-sensitive JNK and p38 MAPKs to enhance skin inflammation [11]. In general, UVB causing JNK and p38 MAPK phosphorylation leads to an increase in proinflammatory cytokine expression. Papavassiliou et al. (2020) suggested that the activation of JNK mostly activated c-Jun phosphorylation at a positive regulatory 
domain: Ser63/73 and Thr91/93 residues. Phosphorylated c-Jun was able to form c-Jun homodimerization or heterodimerization with c-Fos [15]. This event consequently improved the activities of the transcriptional factor subunit of the activator protein 1 (AP-1) complex. The increased AP- 1 activity up-regulated proinflammatory cytokines, including COX2 and iNOS $[8,11,30,37]$. Moreover, Spiegelman et al. (2000) suggested that activation of JNK resulted in the accumulation of $\beta$-transducin repeat-containing protein $(\beta-\operatorname{Tr} C \mathrm{P})$, which mediated the ubiquitination of phosphorylated IKB $\alpha$ protein. This event indicated that JNK plays an important role in the regulation of NF- $\mathrm{KB}$ activation [38]. Likewise, Chen et al. (2002) considered the relationship between JNK and the NF- $\mathrm{KB}$ signaling pathway in inflammatory processes. The report indicated that diverse stimuli, including intra-cellular stresses and UV light, could stimulate JNK activity, potentially linked to the I $\kappa B$ ubiquitination, turning on NF- $\mathrm{kB}$ activities [39]. This evidence correlates with our study, where we found that at $25 \mathrm{~mJ} / \mathrm{cm}^{2}$, UVB induces both c-Jun and p38 activity, as shown in Figure 5. Our results demonstrated that PCS attenuated not only NF- $\mathrm{kB}$ but also phosphorylated c-Jun inhibition in HaCaT cells induced by UVB. Additionally, it is well known that JNK phosphorylation activates the apoptosis pathway through regulating B-cell lymphoma-2 (BCL-2) family proteins, such as Bcl-2 suppression, and the induction of Bcl-2-associated X protein (Bax) translocation to the mitochondria, resulting in apoptosis induction [40]. The current study demonstrated that PCS suppressed sub-G1 content and c-Jun phosphorylation, while previously, studies showed that PCS extract attenuated UVB-induced apoptosis through decreased Bax and increased Bcl-2 levels in UVB-treated cells [17]. Hence, it is possible that the anti-apoptotic activity of PCS extract is through suppressed c-Jun phosphorylation in UVB-treated cells. Similarly, the red raspberry extract and cyanidin-3-glucoside (C3G) inhibited skin damage in UVB-treated HaCaT cells through attenuated p-p38 and p-cJun [35,41-44], while the amla fruit extract attenuated the inflammatory response to UVB by inhibiting AP-1, NF- $\mathrm{KB}$, and mediator PGE2 without any impact on p38 activation [45]. Similarly, PCS extract seems to slightly reduce p38 activity without a statistically significant difference $(p<0.001)$ compared to the UVB-control group. Hence, a deeper understanding of the effect of PCS extract on the molecular mechanism needs to be further studied. Based on these studies, we suggested that PCS extract affects mainly through NF- $\mathrm{KB}$ and c-Jun activity, leading to attenuated UVB-induced skin inflammation in keratinocyte cells.

\section{Materials and Methods}

\subsection{Reagents}

Dulbecco's modified Eagle's medium (DMEM), fetal bovine serum (FBS), penicillinstreptomycin, and trypsin-EDTA were purchased from HiMedia (HiMedia, Laboratories, Mumbai, India). Guava cell cycle ${ }^{\circledR}$ reagent, PVDF membranes, an antibody against iNOS and $\beta$-actin, and chemiluminescence (ECL) reagent were purchased from Merck Millipore (Merck Millipore Corp., Darmstadt, Germany). An antibody against NF-kB, COX-2, p38, phosphorylated-p38, c-Jun, phosphorylated-c-Jun, and anti-mouse/-rabbit secondary antibody conjugated horseradish peroxidase (HRP) were purchased from Cell Signalling (Cell Signalling Technology, Danvers, MA, USA). Anti-mouse secondary antibody conjugated Alexafluoro-546 and fluorescent Hoechst33342 dye were purchased from Thermo Fisher Scientific (Invitrogen ${ }^{\mathrm{TM}}$, Thermo Fisher Scientific Inc., Waltham, MA, USA). Complete Mini Protease Inhibitor Cocktail was purchased from Roche Diagnostics GmbH (Roche Diagnostics GmbH, Mannheim, Germany).

\subsection{Plant Extraction}

The purple stigma of Zea mays L. was used to prepare the PCS extract, which was obtained from Prof. Dr. Malyn Ungsurungsie. The extraction method was as in our previous study [17]. Briefly, the purple corn style was harvested from Khonkaen province, Thailand, and kept in the laboratory at the Plant Breeding Research Centre, Khonkaen University, Thailand (Voucher No. 050914T001). The fresh specimen was dried at $50{ }^{\circ} \mathrm{C}$ in an oven to remove humidity from sample plants. Then, the specimens were ground into 
a powder using an electric blender. After that, $10 \mathrm{~g}$ of dry purple corn silk powder was immersed in $100 \mathrm{~mL}$ of $50 \%$ propylene glycol (PG) for 2 days, followed by the filtration of the extract solution through cheesecloth and filter paper Whatman No.4. Then, the filtrated PCS extract solution was evaporated using a vacuum evaporator and freeze-dried in a lyophilizer. Then, the PCS extract was kept in the dark at $-20{ }^{\circ} \mathrm{C}$ until use.

\subsection{UVB Irradiation System}

A UV incubator (BIO SUN Ultraviolet VILBER LOURMAT) consisting of UVB light $(2 \times 30 \mathrm{~W})$ at a wavelength of $312 \mathrm{~nm}$ was used as a UV source, and the irradiation distance was $25 \mathrm{~mm}$. Cells were placed in $1 \mathrm{~mL}$ of phosphate-buffered saline (PBS) and exposed to a UVB lamp in a UV incubator without a plastic lid. After UVB irradiation, cells were placed in the fresh medium and incubated at $37^{\circ} \mathrm{C}$ and $5 \% \mathrm{CO}_{2}$ in a cell culture incubator (Forma ${ }^{\mathrm{TM}}$ Steri-Cult ${ }^{\mathrm{TM}}$, Thermo Fisher Scientific Inc., Waltham, MA, USA) before subsequent experiments.

\subsection{UV-Absorbing Properties of PCS Extract}

The UV-absorbing properties of PCS extract were investigated. The PCS extract at $1 \mathrm{mg} / \mathrm{mL}$ (in 100\% DMSO) and 100\% DMSO (a negative control) was prepared. Then, the UV-absorbing properties were measured at every $1 \mathrm{~nm}$ covering a range of $280-400 \mathrm{~nm}$ wavelengths using a spectrophotometer (Multiskan Sky, Thermo Fisher Scientific Inc., Waltham, MA, USA). The optical density (OD) of a sample is indicated as the UV-absorbing property of samples.

\subsection{Cell Culture}

The human keratinocyte $\mathrm{HaCaT}$ cell line was purchased from American Type Culture Collection (ATCC, Manassas, VA, USA). The cells were maintained in DMEM medium supplemented with $10 \%$ FBS, $100 \mathrm{U} / \mathrm{mL}$ penicillin, and $100 \mu \mathrm{g} / \mathrm{mL}$ streptomycin in $\mathrm{T} 75$ tissue culture flasks as a monolayer. Cells were grown in a humidified incubator at $37^{\circ} \mathrm{C}$ and $5 \% \mathrm{CO}_{2}$. At $80 \%$ confluence every $2-3$ days, cells were subcultured by $0.25 \%$ trypsin-EDTA.

\subsection{Flow Cytometry}

Cells were seeded in $30 \times 10^{4}$ cells / well overnight and pre-treated with PCS extract at concentrations of $0.3,0.5$, and $1 \mathrm{mg} / \mathrm{mL}$ for $1 \mathrm{~h}$. Then, the cells were exposed to $25 \mathrm{~mJ} / \mathrm{cm}^{2}$ $\mathrm{UVB}$ and incubated with fresh medium at $37^{\circ} \mathrm{C}$ for $24 \mathrm{~h}$ before being harvested using $0.25 \%$ trypsin-EDTA. Then, the supernatant was removed by centrifugation at $2000 \mathrm{rpm}$ for $3 \mathrm{~min}$. Cell pellets were fixed with $70 \%$ ice-cold ethanol, then washed and stained with Guava cell cycle ${ }^{\circledR}$ reagent for $30 \mathrm{~min}$ at room temperature in the dark. The sub-G1 content was determined using a Guava EasyCyte ${ }^{\mathrm{TM}}$ flow cytometer and GuavaSoft ${ }^{\mathrm{TM}}$ software (Merck Millipore Crop., Darmstadt, Germany).

\subsection{Immunofluorescence NF- $\kappa B$ Staining}

$\mathrm{HaCaT}$ cells were grown on glass coverslips in $35 \mathrm{~mm}$ culture dishes $\left(30 \times 10^{4}\right.$ cells/well) overnight. Cells were pre-treated with PCS extract at concentrations of $0.3,0.5$, and $1 \mathrm{mg} / \mathrm{mL}$ for $1 \mathrm{~h}$ followed by the UVB exposure, then incubated at $37^{\circ} \mathrm{C}$ for $1 \mathrm{~h}$. After that, cells were fixed with $4 \%$ paraformaldehyde for 10 min and permeabilized with $0.5 \%$ Triton X-100. Then, cells were blocked with $3 \%$ bovine serum albumin (BSA) and incubated with an antibody against NF- $\mathrm{kB}(1: 250)$ at $4{ }^{\circ} \mathrm{C}$ overnight. After incubation, cells were incubated with secondary antibody conjugated with Alexafluoro-546 (1:500) at room temperature, and the nuclei were stained with $5 \mu \mathrm{g} / \mathrm{mL}$ of Hoechst33342 dye. The fluorescence signals were observed under a fluorescent microscope (IX71 Olympus, Tokyo, Japan).

\subsection{Western Blot Analysis}

After treatment, cells were collected by scraping and lysis with RIPA lysis buffer (50 mM Tris-HCl, $5 \mathrm{mM}$ EDTA, $250 \mathrm{mM} \mathrm{NaCl}, 0.5 \%$ Triton X-100, pH 7.5) containing 
PMSF and a complete mini protease inhibitor cocktail. Then, protein concentrations were determined using Bradford assay solution kits (Bio-Rad Laboratories, Hercules, CA, USA). The protein samples were separated by gel electrophoresis (SDS-PAGE) and transferred from acrylamide gels onto PVDF membranes using a Mini Trans-Blot Cell ${ }^{\circledR}$ (Bio-Rad Laboratories, Hercules, CA, USA) before blocking the non-specific bands with 5\% skim milk. Then, proteins on membranes were probed with the antibodies against NF- $\mathrm{B}, \mathrm{COX}-$ 2, iNOS, p38, p-p38, c-Jun, p-c-Jun, and $\beta$-actin at dilution of 1:1000 (5\% BSA) at $4{ }^{\circ} \mathrm{C}$ overnight. After that, membranes were incubated with horseradish peroxidase (HRP)conjugated secondary antibodies for $1 \mathrm{~h}$. Then, a chemiluminescence (ECL) reagent was added to enhance the immunoreactive signals. The protein expression was visualized by using a charge-coupled device (CCD) camera in a gel documentary machine (UVITEC, Alliance Q9 Advanced, Cambridge, UK).

\subsection{Statistical Analysis}

All data are shown as the mean \pm standard deviation (SD) of three independent experiments. SPSS version 20.0 (SPSS, Inc., Chicago, IL, USA) was used to evaluate a statistical significance comparison by ANOVA using Tukey's post hoc test. Values at $p<0.05, p<0.01$ and $p<0.001$ were considered as statistically significant differences. The relative protein band intensity was quantified by Image J densitometer.

\section{Conclusions}

In conclusion, we found that the PCS extract presented the ability to attenuate the inflammation in human keratinocyte cells by mainly suppressing the activation of NF- $k B$ and c-Jun, resulting in the decrease in inflammatory cytokines COX-2 and iNOS. Therefore, the PCS extract may be suitable for development as a novel natural inflammatory preventive agent due to the UVB exposure of the skin.

Author Contributions: Investigation and writing-original draft preparation, W.P.; writing-review and editing, S.I.; resources (extract preparation), M.U.; supervision, funding acquisition and validation, R.W. All authors have read and agreed to the published version of the manuscript.

Funding: This research was funded by Research and Researcher for Industries (RRi), the Thailand Research Fund (TRF) corroboration with S and J International Enterprises Public Company Limited, Bangkok, Thailand, grant number PHD57I0075.

Institutional Review Board Statement: Not applicable.

Informed Consent Statement: Not applicable.

Data Availability Statement: The datasets analyzed during the current study are available from the corresponding author on reasonable request.

Acknowledgments: We would like to thank the Research Division, Faculty of Medicine, Srinakharinwirot University, Bangkok, Thailand.

Conflicts of Interest: The authors declare no conflict of interest.

\section{References}

1. Afaq, F.; Mukhtar, H. Effects of solar radiation on cutaneous detoxification pathways. J. Photochem. Photobiol. B 2001, 63, 61-69. [CrossRef]

2. Ivan, A.L.; Campanini, M.Z.; Martinez, R.M.; Ferreira, V.S.; Steffen, V.S.; Vicentini, F.T.; Vilela, F.M.; Martins, F.S.; Zarpelon, A.C.; Cunha, T.M.; et al. Pyrrolidine dithiocarbamate inhibits UVB-induced skin inflammation and oxidative stress in hairless mice and exhibits antioxidant activity in vitro. J. Photochem. Photobiol. B 2014, 138, 124-133. [CrossRef] [PubMed]

3. Park, G.; Kim, H.G.; Hong, S.P.; Kim, S.Y.; Oh, M.S. Walnuts (seeds of Juglandis sinensis L.) protect human epidermal keratinocytes against UVB-induced mitochondria-mediated apoptosis through upregulation of ROS elimination pathways. Skin Pharmacol. Physiol. 2014, 27, 132-140. [CrossRef] [PubMed]

4. Lee, C.; Park, G.H.; Ahn, E.M.; Kim, B.A.; Park, C.I.; Jang, J.H. Protective effect of Codium fragile against UVB-induced proinflammatory and oxidative damages in HaCaT cells and BALB/c mice. Fitoterapia 2013, 86, 54-63. [CrossRef] 
5. Chatterjee, S. Oxidative Stress. Inflammation and Disease. In Oxidative Stress and Biomaterials; Dziubla, T., Ed.; Academic Press: Cambridge, MA, USA, 2016; pp. 35-58.

6. Kawashima, S.; Funakoshi, T.; Sato, Y.; Saito, N.; Ohsawa, H.; Kurita, K.; Nagata, K.; Yoshida, M.; Ishigami, A. Protective effect of pre- and post-vitamin C treatments on UVB-irradiation-induced skin damage. Sci. Rep. 2018, 8, 16199. [CrossRef]

7. Liu, X.; Shi, S.; Ye, J.; Liu, L.; Sun, M.; Wang, C. Effect of polypeptide from Chlamys farreri on UVB-induced ROS/NF-kappaB/COX2 activation and apoptosis in HaCaT cells. J. Photochem. Photobiol. B. 2009, 96, 109-116. [CrossRef] [PubMed]

8. Hur, S.; Lee, Y.S.; Yoo, H.; Yang, J.H.; Kim, T.Y. Homoisoflavanone inhibits UVB-induced skin inflammation through reduced cyclooxygenase-2 expression and NF-kappaB nuclear localization. J. Dermatol. Sci. 2010, 59, 163-169. [CrossRef] [PubMed]

9. Isoherranen, K.; Punnonen, K.; Jansen, C.; Uotila, P. Ultraviolet irradiation induces cyclooxygenase-2 expression in keratinocytes. Br. J. Dermatol. 1999, 140, 1017-1022. [CrossRef]

10. Choi, Y.J.; Moon, K.M.; Chung, K.W.; Jeong, J.W.; Park, D.; Kim, D.H.; Yu, B.P.; Chung, H.Y. The underlying mechanism of proinflammatory NF-kappaB activation by the mTORC2/Akt/IKKalpha pathway during skin aging. Oncotarget 2016, 7, 52685-52694. [CrossRef] [PubMed]

11. Shin, S.W.; Jung, E.; Kim, S.; Kim, J.H.; Kim, E.G.; Lee, J.; Park, D. Antagonizing effects and mechanisms of afzelin against UVB-induced cell damage. PLoS ONE 2013, 8, e61971. [CrossRef]

12. Zhi, Q.; Lie, L.; Li, F.; Zhao, J.; Yin, R.; Ming, J. The anthocyanin extracts from purple-fleshed sweet potato exhibited antiphotoaging effects on ultraviolent B-irradiated BALB/c-nu mouse skin. J. Funct. Foods 2020, 64, 103640. [CrossRef]

13. Kuanpradit, C.; Jaisin, Y.; Jungudomjaroen, S.; Akter, M.S.; Puttikamonkul, S.; Sobhon, P.; Cummins, S.F. Attenuation of UV-B exposure-induced inflammation by abalone hypobranchial gland and gill extracts. Int. J. Mol. Med. 2017, 39, 1083-1090. [CrossRef] [PubMed]

14. Jiang, F.; Guan, H.; Liu, D.; Wu, X.; Fan, M.; Han, J. Flavonoids from sea buckthorn inhibit the lipopolysaccharide-induced inflammatory response in RAW264.7 macrophages through the MAPK and NF-kappaB pathways. Food Funct. 2017, 8, 1313-1322 [CrossRef] [PubMed]

15. Papavassiliou, A.G.; Musti, A.M. The Multifaceted output of c-Jun biological activity: Focus at the junction of CD8 T cell activation and exhaustion. Cells 2020, 9, 2470. [CrossRef]

16. Khan, N.; Syed, D.N.; Pal, H.C.; Mukhtar, H.; Afaq, F. Pomegranate fruit extract inhibits UVB-induced inflammation and proliferation by modulating NF-kappaB and MAPK signaling pathways in mouse skin. Photochem. Photobiol. 2012, 88, 1126-1134. [CrossRef]

17. Poorahong, W.; Innalak, S.; Ungsurungsie, M.; Watanapokasin, R. Protective effect of purple corn silk extract against ultraviolet-Binduced cell damage in human keratinocyte cells. J. Adv. Pharm. Technol. Res. 2021, 12, 140-146.

18. Ramos-Escudero, F.; Muñoz, A.M.; Alvarado-Ortíz, C.; Alvarado, Á.; Yáñez, J.A. Purple corn (Zea mays L.) phenolic compounds profile and its assessment as an agent against oxidative stress in isolated mouse organs. J. Med. Food. 2012, 15, 206-215. [CrossRef]

19. Pedreschi, R.; Cisneros-Zevallos, L. Antimutagenic and antioxidant properties of phenolic fractions from Andean purple corn (Zea mays L.). J. Agric. Food Chem. 2006, 54, 4557-4567. [CrossRef]

20. Ebrahimzadeh, M.A.; Pourmorad, P.; Hafezi, S. Antioxidant activities of Iranian corn silk. Turk. J. Biol. 2008, 32, 43-49.

21. Zilic, S.; Jankovic, M.; Basic, Z.; Vancetovic, J.; Maksimovic, V. Antioxidant activity, phenolic profile, chlorophyll and mineral matter content of corn silk (Zea mays L): Comparison with medicinal herbs. J. Cereal Sci. 2016, 69, 363-370. [CrossRef]

22. Chaiittianan, R.; Sutthanut, K.; Rattanathongkom, A. Purple corn silk: A potential anti-obesity agent with inhibition on adipogenesis and induction on lipolysis and apoptosis in adipocytes. J. Ethnopharmacol. 2017, 6, 9-16. [CrossRef] [PubMed]

23. Sarepoua, E.; Tangwongchai, R.; Suriharn, B.; Lertrat, K. Relationships between phytochemicals and antioxidant activity in corn silk. Int. Food Res. J. 2013, 20, 2073-2079.

24. Senphan, T.; Yakong, N.; Aurtae, K.; Songchanthuek, S.; Choommongkol, V.; Fuangpaiboon, N.; Phing, P.L.; Yarnpakdee, S Comparative studies on chemical composition and antioxidant activity of corn silk from two varieties of sweet corn and purple waxy corn as influenced by drying methods. Food Appl. Biosci. J. 2019, 7, 64-80.

25. Perez-Sanchez, A.; Barrajon-Catalan, E.; Herranz-Lopez, M.; Castillo, J.; Micol, V. Lemon balm extract (Melissa officinalis L.) promotes melanogenesis and prevents UVB-induced oxidative stress and DNA damage in a skin cell model. J. Dermatol. Sci. 2016, 84, 169-177. [CrossRef]

26. Tsoyi, K.; Park, H.B.; Kim, Y.M.; Chung, J.I.; Shin, S.C.; Lee, W.S.; Seo, H.G.; Lee, J.H.; Chang, K.C.; Kim, H.J. Anthocyanins from black soybean seed coats inhibit UVB-induced inflammatory cylooxygenase-2 gene expression and PGE2 production through regulation of the nuclear factor-kappaB and phosphatidylinositol 3-kinase/Akt pathway. J. Agric. Food Chem. 2008, 56, 8969-8974. [CrossRef]

27. Buckman, S.Y.; Gresham, A.; Hale, P.; Hruza, G.; Anast, J.; Masferrer, J.; Pentland, A.P. COX-2 expression is induced by UVB exposure in human skin: Implications for the development of skin cancer. Carcinogenesis 1998, 19, 723-729. [CrossRef]

28. Yang, Z.; Zhai, W. Identification and antioxidant activity of anthocyanins extracted from the seed and cob of purple corn (Zea mays L.). Innov. Food Sci. Emerg. Technol. 2010, 11, 169-176. [CrossRef]

29. Zhang, Z.; Zhou, B.; Wang, H.; Wang, F.; Song, Y.; Liu, S.; Xi, S. Maize purple plant pigment protects against fluoride-induced oxidative damage of liver and kidney in rats. Int. J. Environ. Res. Public Health 2014, 11, 1020-1033. [CrossRef]

30. Park, C.; Park, J.; Kim, W.J.; Kim, W.; Cheong, H.; Kim, S.J. Malonic acid isolated from Pinus densiflora inhibits UVB-induced oxidative stress and inflammation in HaCaT keratinocytes. Polymers 2021, 13, 816. [CrossRef] 
31. Li, X.Q.; Cai, L.M.; Liu, J.; Ma, Y.L.; Kong, Y.H.; Li, H.; Jiang, M. Liquiritin suppresses UVBinduced skin injury through prevention of inflammation, oxidative stress and apoptosis through the TLR4/MyD88/NFkappaB and MAPK/caspase signaling pathways. Int. J. Mol. Med. 2018, 42, 1445-1459.

32. Hinata, K.; Gervin, A.M.; Jennifer-Zhang, Y.; Khavari, P.A. Divergent gene regulation and growth effects by NF-kappa B in epithelial and mesenchymal cells of human skin. Oncogene 2003, 22, 1955-1964. [CrossRef] [PubMed]

33. Han, Y.; Jiang, Q.; Gao, H.; Fan, J.; Wang, Z.; Zhong, F.; Zheng, Y.; Gong, Z.; Wang, C. The anti-apoptotic effect of polypeptide from Chlamys farreri (PCF) in UVB-exposed HaCaT cells involves inhibition of iNOS and TGF-beta1. Cell Biochem. Biophys. 2015, 71, 1105-1115. [CrossRef] [PubMed]

34. Liu, T.; Zhang, L.; Joo, D.; Sun, S.C. NF-kappaB signaling in inflammation. Signal. Transduct. Target. Ther. 2017, 2, 17023. [CrossRef] [PubMed]

35. Wang, P.W.; Cheng, Y.C.; Hung, Y.C.; Lee, C.H.; Fang, J.Y.; Li, W.T.; Wu, Y.R.; Pan, T.L. Red raspberry extract protects the skin against UVB-induced damage with antioxidative and anti-inflammatory properties. Oxid. Med. Cell Longev. 2019, 9529676. [CrossRef] [PubMed]

36. Gasparrini, M.; Forbes-Hernandez, T.Y.; Afrin, S.; Reboredo-Rodriguez, P.; Cianciosi, D.; Mezzetti, B.; Quiles, J.L.; Bompadre, S.; Battino, M.; Giampieri, F. Strawberry-based cosmetic formulations protect human dermal fibroblasts against UVA-induced damage. Nutrients 2017, 14, 605. [CrossRef] [PubMed]

37. Piao, M.J.; Kang, K.A.; Zhen, A.X.; Kang, H.K.; Koh, Y.S.; Kim, B.S.; Hyun, J.W. Horse oil mitigates oxidative damage to human HaCaT keratinocytes caused by ultraviolet B irradiation. Int. J. Mol. Sci. 2019, 25, 1490. [CrossRef]

38. Spiegelman, V.S.; Slaga, T.J.; Pagano, M.; Minamoto, T.; Ronai, Z.; Fuchs, S.Y. Wnt/beta-catenin signaling induces the expression and activity of betaTrCP ubiquitin ligase receptor. Mol. Cell. 2000, 5, 877-882. [CrossRef]

39. Chen, F.; Bower, J.; Demers, L.M.; Shi, X. Upstream Signal Transduction of NF-kB Activation. Atlas Genet. Cytogenet. Oncol. Haematol. 2002, 6, 156-170. [CrossRef]

40. Yue, J.; López, J.M. Understanding MAPK Signaling Pathways in Apoptosis. Int. J. Mol. Sci. 2020, 21, 2346. [CrossRef]

41. Gao, W.; Wang, Y.S.; Hwang, E.; Lin, P.; Bae, J.; Seo, S.A.; Yan, Z.; Yi, T.H. Rubus idaeus L. (red raspberry) blocks UVB-induced MMP production and promotes type I procollagen synthesis via inhibition of MAPK/AP-1, NF-kappabeta and stimulation of TGF-beta/Smad, Nrf2 in normal human dermal fibroblasts. J. Photochem. Photobiol. B 2018, 185, 241-253. [CrossRef]

42. Hu, Y.; Ma, Y.; Wu, S.; Chen, T.; He, Y.; Sun, J.; Jiao, R.; Jiang, X.; Huang, Y.; Deng, L.; et al. Protective effect of cyanidin-3-oglucoside against ultraviolet B radiation-induced cell damage in human HaCaT keratinocytes. Front. Pharmacol. $2016,7,301$. [CrossRef]

43. Cimino, F.; Ambra, R.; Canali, R.; Saija, A.; Virgili, F. Effect of cyanidin-3-o-glucoside on UVB-induced response in human keratinocytes. J. Agric. Food Chem. 2006, 54, 4041-4047. [CrossRef]

44. Pratheeshkumar, P.; Son, Y.O.; Wang, X.; Divya, S.P.; Joseph, B.; Hitron, J.A.; Wang, L.; Kim, D.; Yin, Y.; Roy, R.V.; et al. Cyanidin3-glucoside inhibits UVB-induced oxidative damage and inflammation by regulating MAP kinase and NF-kappaB signaling pathways in SKH-1 hairless mice skin. Toxicol. Appl. Pharmacol. 2014, 280, 127-137. [CrossRef] [PubMed]

45. Kunchana, K.; Jarisarapurin, W.; Chularojmontri, L.; Wattanapitayakul, S.K. Potential Use of Amla (Phyllanthus emblica L.) Fruit Extract to Protect Skin Keratinocytes from Inflammation and Apoptosis after UVB Irradiation. Antioxidants 2021, 10, 703. [CrossRef] [PubMed] 